\title{
Masonry behaviour and modelling
}

\author{
Maurizio Angelillo $o^{\ddagger}$, Paulo B. Lourenço ${ }^{*}$ and Gabriele Milani ${ }^{\dagger}$ \\ ‡ Department of Civil Eng., University of Salerno, Italy \\ * Department of Civil Eng., University of Minho, Portuga \\ $\dagger$ Department of Struct. Eng. Geotech., Politec IC di Milano, haly
}

\begin{abstract}
In this Chapter we present the basic experimental facts on masonry materials and introduce simple and refined models for masonry. The simple models are essentially macroscopic and based on the assumption that the material is incapable of sustaining tensile loads (No-Tension assumption). The refined models account for the microscopic structure of masonry, modeling the interaction between the blocks and the interfaces.
\end{abstract}

\section{Premise}

The first basic question that any course on Masonry Structures should address is: what we consider as masonry material?

Masonry structures can be built with a large variety of materials, masonry blocks can be of different types and assembled in many different ways; mortar, if present, can also be of various kinds, and the way it interacts with the blocks depends on workmanship. There is old masonry, new masonry and a peculiar place is taken by brickworks.

There are essentially two ways of approaching the modelling of masonry: the first one is rather ambitious and aims at the modelling of large classes of masonry buildings (e.g. old masonry structures). The second one is more pragmatic and restricts to the mechanical description of very specific types of masonry (masonry structures of regularly arranged blocks, e.g. brickworks of known geometry). Here Silhavi, Lucchesi and myself adopt the first approach and Sacco, Lebon, and Lourenco \& Milani propose the second one (also if Sacco has had experiences and papers where the first approach was considered).

It is evident that with the second approach the models adopted can be very sophisticated and more close to reality, whilst the first approach asks for very crude material assumptions and produces predictions on real 
constructions that are affected by large approximations. The point is that, often, the real geometry and material behaviour of the building is not known in the detail required by the second approach, the definition of even the most primitive material parameters, such as strength and stiffness, being generally difficult and affected by an elevated randomness and uncertainty.

The most basic assumption that can be made, in view of the small and often erratic value of the tensile strength of masonry materials, is that the material behaves unilaterally, that is only compressive stresses can be transmitted (No-Tension assumption). It is generally recognized (since the pioneering work of Heyman (1966) that such an assumption is the first clue for the interpretation of masonry behaviour; on adopting and applying it, we acquire the eyes to appreciate and interpret the fracture patterns, that is the masonry most peculiar manifestation, representing, in a sense, its breath (that is the way in which the masonry buildings relieve and can survive also to radical and, sometimes, dramatic changes of the environment).

We call the models based on the No-Tension assumption simple models and the models accounting for more sophisticate stress-strain laws (i.e. exhibiting damage, softening, brittleness) or based on the micro/meso-scopic structure of the material, refined models. The book is divided into two interconnected but separate parts: Part I, where the simplified models are studied, Part II where the refined models are described.

In the present Chapter we discuss the basic experimental facts on masonry materials justifying the introduction of the simple and refined models for masonry.

\section{Basic behaviour of masonry and simplified unilateral models}

M. Angelillo

\section{$2.1 \quad$ Local failure modes}

There are basically three failure modes that are visible locally in masonry structures.

1. The first one is the one associated to the brittleness of the material and that manifests itself with detachment fractures, such as those reported in Figure 1. Such fractures consist in cracks that usually separate neatly two parts of seemingly intact material and are usually the "good" ones, that is those contributing to the accommodation and release of stress.

2. The second one is a kind of mixed mode in which fractures of de- 

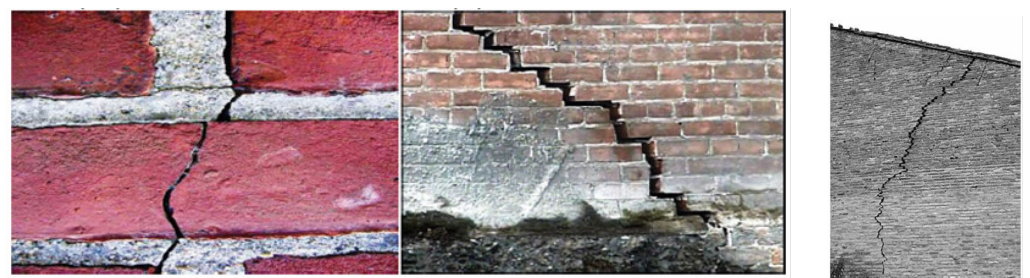

Figure 1. Fracture of detachment in brick walls at different scales

tachment alternate to lines of sliding, such as those appearing in the examples of in-plane shear shown in Figure 2. This mode of failure presents usually itself in walls subjected to compressive loads and shears.
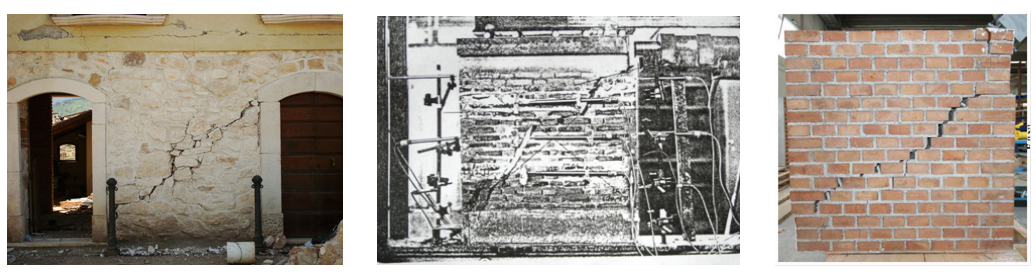

Figure 2. Detachment and sliding due to combined compression and shear.

3. The third failure mode is the so-called crushing of the material (Figure 3) and occurs essentially under compression. By looking closely to this failure mode one can see again that it consists of finer detachment fractures, close together and separated by damaged material, having sometimes the consistence of powder.
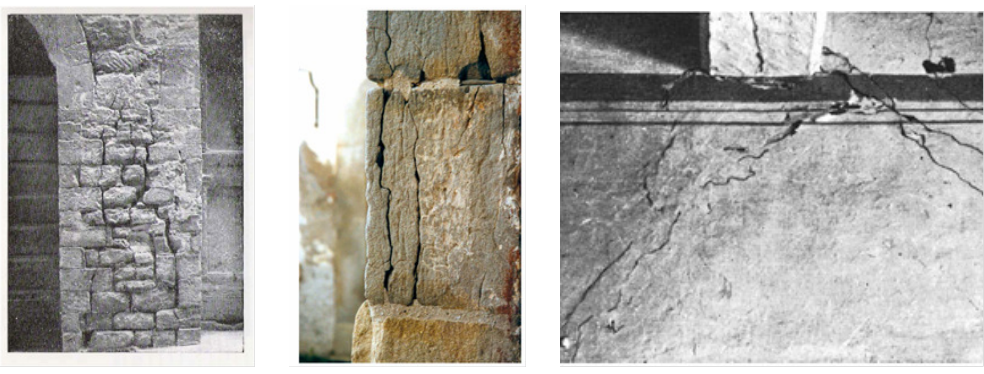

Figure 3. Crushing due to compression. 
The second and third modes often occur when the load is critical or close to become a collapse load. The third one is the most dangerous since failure under compression is usually sudden.

\subsection{Structural failure mechanisms}

Besides crushing of compressed members, such as those shown in Figure 3 , there are basically other two structural failure mechanisms through which a masonry structure (or a part of it) may collapse. The most frequent one, under seismic loads, is out of plane rocking as shown in Figure 4. Such a mechanism can be due to the effect of the self load solely, or can be favoured by the pushing of the roof, or the hammering of a heavy floor or ceiling.
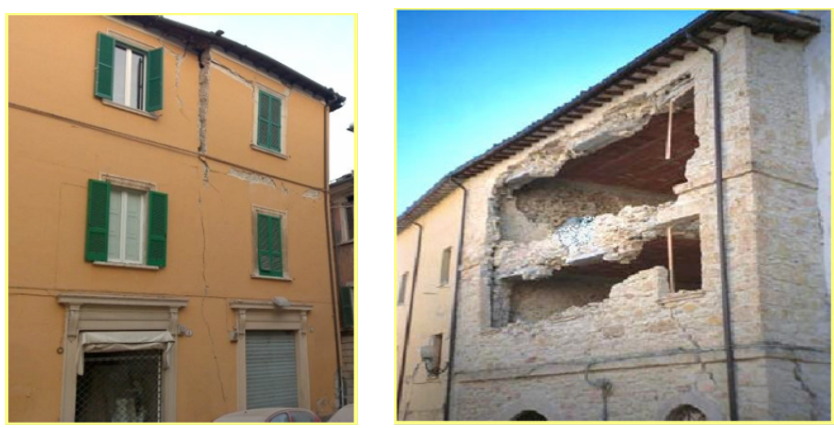

Figure 4. Out of plane rocking.

Both crushing failure and out of plane rocking are usually the result of a poor design, or of unwise modifications of the original construction. To avoid out of plane rocking many regulations prescribe the maximum distance between two consecutive transverse walls. The demolition of such transverse walls is an example of a risky modification.

The third failure mechanism, that is in-plane shear, is the one proper of well designed buildings, that is structures sustaining the horizontal actions through the harmonized cooperation of the shear resistant structures (Figure 5), i.e. with local failure modes of their masonry units, of the type shown in Figure 2.

The reader must be warned that also the detachment fractures, due to settlement or accommodation of the structure to new loads or to environmental changes, usually physiological and not necessarily entailing an imminent danger, may be the precursors of an incipient collapse: if the amplitude of the displacements and the size of the cracks become comparatively large 

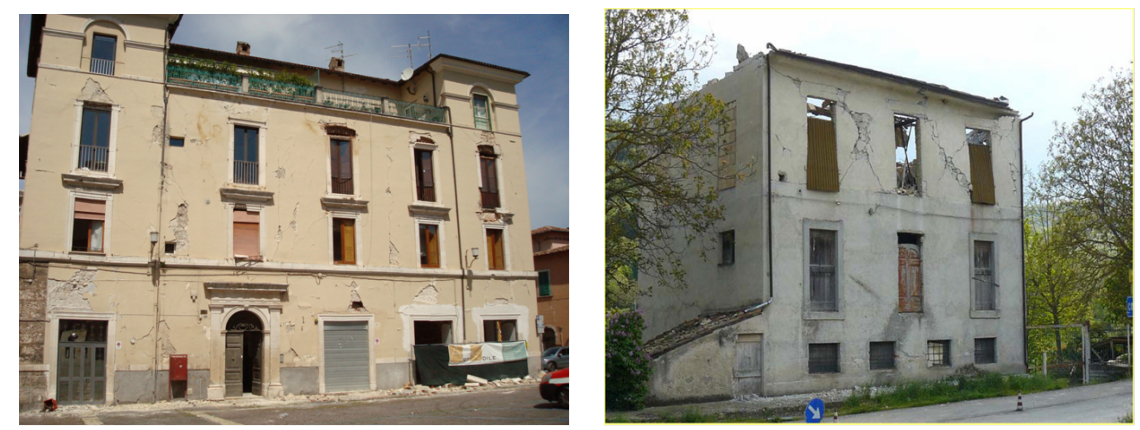

Figure 5. In plane failure due to compression and shear.

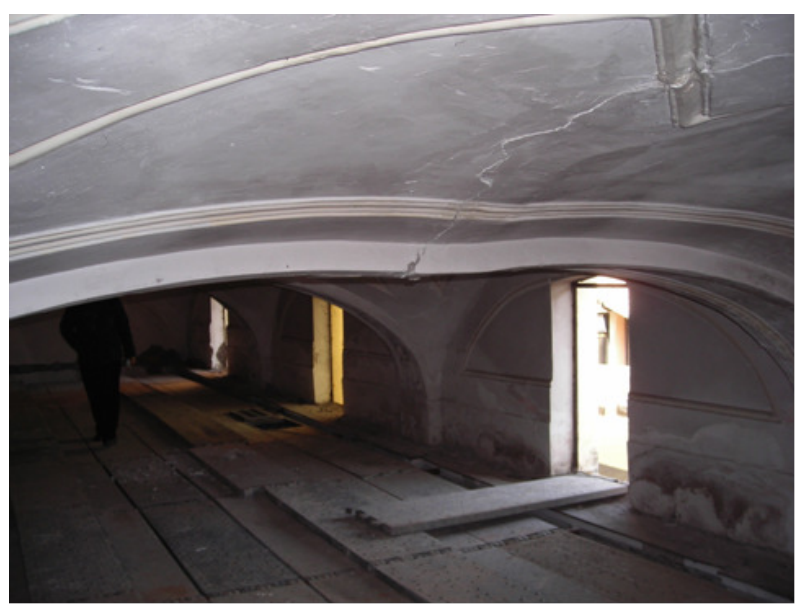

Figure 6. Incipient failure of a shallow cross vault due to excessive spread of the abutments (aisle vaults of a XVI century chapel in Nocera Inferiore (SA), Italy). Courtesy of Enrico Sicignano. 
with respect to the overall size of the structure, they could allow for the structure to become unstable. As an example, an arch or a vault may be perfectly comfortable under the action of their own weight, in a fractured and heavily distorted configuration, until the displacements grow to be so large that a mechanism becomes possible and their overall stability is suddenly lost. An example of such extreme conditions is reported in Figure 6. The message is that detachment fractures are usually unwary, but it is wise checking the size of cracks and displacements and their evolution in time.

\subsection{Experimental observations: results of typical tests}

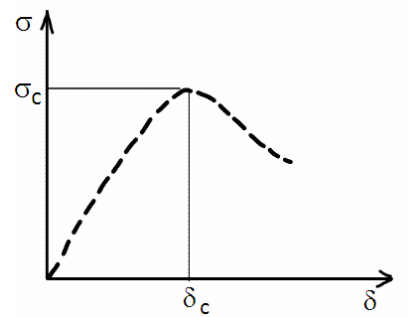

(a)

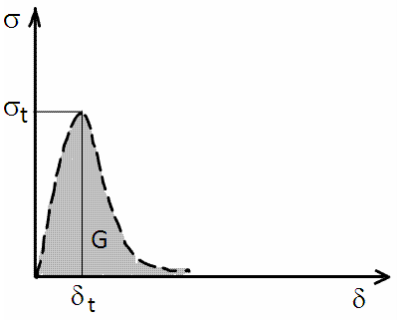

(b)

Figure 7. Typical stress-displacement plot for a masonry material. (a) compression, (b) tension. In (b) the shaded area labelled $G$ is the toughness, that is the surface energy per unit area that must be expended to open a crack. The plots are only qualitative; for any kind of masonry, usually, the values of $\sigma_{c}$ and $\sigma_{t}$ differ of at least one order of magnitude.

Old master masons could perfectly build without the help of tests on the construction materials. Nowadays the situation, compared to ancient times (when the predominance of metaphysics on physics was absolute, see Benvenuto (1991)), is entirely different and no work on buildings can proceed in absence of an experimental assessment on material performances.

Masonry is a composite material and accurate tests can be performed on the component materials, on masonry assemblies and on small masonry structures. The detailed description of some of these tests will be touched elsewhere in this book (Lourenco \& Milani), here I consider the results of typical tests on small masonry walls, in order to extract the main aspects of masonry behaviour that can be captured by the simple models.

In Figure 7 the typical aspect of the stress-displacement plots corresponding to simple compression and tension load tests on masonry walls are reported. The strength of the wall depends on the strength of the individual components (masonry units/blocks and mortar): some regulations 


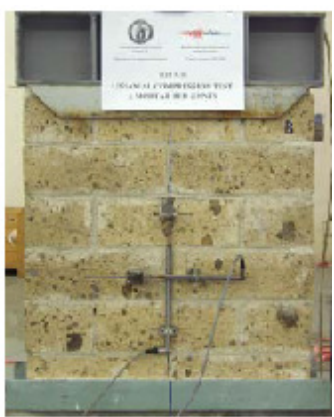

(a)

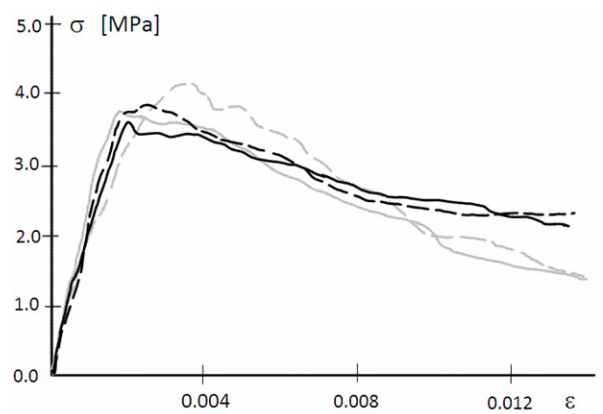

(b)

Figure 8. Simple compression tests on masonry walls made of tuff blocks. (a) test set up, (b) stress strain plots corresponding to four different tests on walls having identical geometry and material components. Courtesy of F. Nardone (2006).

give formulas to relate the compressive strength of masonry to the compressive strength of the components, also if the reliability of such rules is questionable on many grounds.

As the example reported in Figure 8, relative to compression tests on tuff masonry walls $(50 \mathrm{~cm} \times 60 \mathrm{~cm} \times 20 \mathrm{~cm})$ made of the same kind of stones and mortar, show, the results are affected by a strong variance, both for strength and stiffness. Such a state of affairs is even worse in the case of tension where a reliable value of strength is hardly identifiable with the standard statistical methods. Therefore we point out that the graphs of Figure 7 have to be interpreted as the uniaxial stress-displacement plots of a highly idealized masonry material.

The main feature of masonry materials is that the tensile strength $\sigma_{t}$ is much lower than the compressive strength $\sigma_{c}$ : the ratio $\sigma_{t} / \sigma_{c}$ is usually lower than 0.1 and can be as low as 0.01 or even, locally, vanishingly small.

Masonry behaves essentially as an elastic material in compression up to $80-90 \%$ of the strength, also if due to early microcracking and damage the stress-strain plot is definitely nonlinear. In the post critical phase the material undergoes irreversible deformations, showing a sort of plastic behaviour. Therefore the stress-strain plot of a typical masonry-like bar can be represented by the graph of Figure 9a.

For book keeping the reference strength and stiffness of some common masonry materials are listed in Table 1 . Notice that $\sigma_{c}$ is the compressive strength and that the shear strength $\tau_{s}$ is roughly correlated to the tensile strength $\sigma_{t}$ through the relation $\tau_{s} \approx \sigma_{t} / 2$. 


\begin{tabular}{|l|c|c|c|c|}
\hline Masonry Type & $\sigma_{c}\left(\frac{d a N}{c m^{2}}\right)$ & $\tau_{s}\left(\frac{d a N}{c m^{2}}\right)$ & $E\left(\frac{d a N}{c m^{2}}\right)$ & $\rho\left(\frac{K g}{m^{3}}\right)$ \\
\hline $\begin{array}{l}\text { Disarranged masonry } \\
\text { of cobbles/boulders }\end{array}$ & $10-18$ & $0.20-0.32$ & $6900-10500$ & 1900 \\
\hline $\begin{array}{l}\text { Masonry of } \\
\text { roughhewed stones }\end{array}$ & $20-30$ & $0.35-0.51$ & $10200-14400$ & 2000 \\
\hline $\begin{array}{l}\text { Masonry of } \\
\text { cut stones }\end{array}$ & $14-24$ & $0.56-0.74$ & $15000-19800$ & 2100 \\
\hline $\begin{array}{l}\text { Masonry of } \\
\text { soft stones }\end{array}$ & $60-80$ & $0.90-1.20$ & $24000-32000$ & 2200 \\
\hline $\begin{array}{l}\text { Masonry of } \\
\text { squared stone blocks }\end{array}$ & $24-40$ & $0.60-0.92$ & $12000-18000$ & 1800 \\
\hline $\begin{array}{l}\text { Brickwork of solid } \\
\text { bloks and lime mortar }\end{array}$ & $50-80$ & $2.40-3.20$ & $35000-56000$ & 1500 \\
\hline $\begin{array}{l}\text { Brickwork of semisolid } \\
\text { blocks and cem. mortar }\end{array}$ & $40-60$ & $3.00-4.00$ & $36000-54000$ & 1200 \\
\hline $\begin{array}{l}\text { Brickwork of } \\
\text { air bricks (45\%) }\end{array}$ & $30-40$ & $1.00-1.30$ & $27000-36000$ & 1100 \\
\hline $\begin{array}{l}\text { Brickwork of } \\
\text { air bricks (<45\%) }\end{array}$ & $30-44$ & $1.80-2.40$ & $24000-35200$ & 1400 \\
\hline $\begin{array}{l}\text { Masonry of concrete } \\
\text { air-blocks (45-65\%) }\end{array}$ & $15-20$ & $0.95-1.25$ & $12000-16000$ & 1200 \\
\hline $\begin{array}{l}\text { Masonry of concrete } \\
\text { air-blocks (<45\%) }\end{array}$ & & & 1600 \\
\hline
\end{tabular}

Table 1. Densities and reference mechanical strength and stiffness of different types of coarse masonry with poor mortar. Strength in compression and shear: $\sigma_{c}, \tau_{s}, E$ : Young modulus, $\rho$ : density. Source: Italian Code for Constructions (DM 14.1.2008).

\subsection{Simplified uniaxial models}

In Part I of the present book, basically three simplified models for idealizing the uniaxial masonry-like behaviour will be used. I call them model $z e r o$, one and two, these names coming from the number of parameters that are required for their definition. The order in which the models are put, is an order of gradual improvement.

We must observe explicitly that the first model is not, as one usually expects for any canonical solid, the linear elastic material. There is of course the possibility of modelling masonry structures as linearly elastic: masonry material is definitely an elastic brittle material for very small stress and strains, but the point is that the levels of stress and strains at which masonry materials work in real structures, are usually higher. 
Model zero (RNT). As a first approximation to the behaviour of Figure 9a, the Rigid No-Tension material has been proposed (Figure 9b). This crude unilateral model that describes the material as indefinitely strong and stiff in compression but incapable of sustaining tensile stresses, was first rationally introduced by Heyman (1966) and divulgated and extended in Italy thanks to the effort of Salvatore Di Pasquale (1984) and other distinguished members of the Italian school of Structural Mechanics (see below for an extensive reference). This material is rigid in compression and can elongate freely, a positive deformation of the bar being interpreted as a measure of fracture into the material (either smeared or concentrated). It must be observed that, though the material has a limited repertoire of admissible stresses and strains and exhibits fractures, its uniaxial behaviour in elongation is elastic.

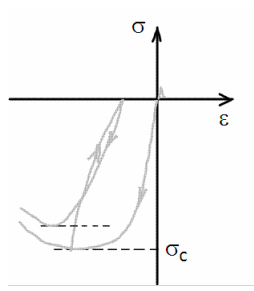

a

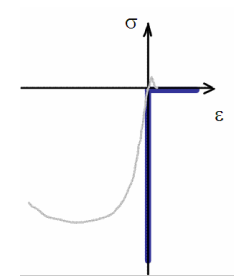

$\mathrm{b}$

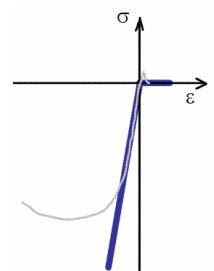

$\mathrm{C}$

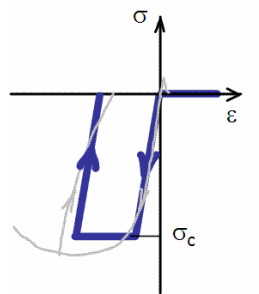

d

Figure 9. Typical uniaxial behaviour, (a), and simplified models: (b) model zero, (c) model one, (d) model two.

This statement, that may appear "paradoxical", derives from the primitive definition of elasticity: stress determined by strain, and the stress has actually a definite value (zero) if the bar elongates. The behaviour is indeed perfectly reversible in elongation, also if deformation occurs without accumulation of elastic energy. We may also notice that there is a degenerate elastic energy associated to this material $(\Phi=0$ if $\epsilon$ is non negative, $\Phi=+\infty$ otherwise) and that the constraint on strain makes the compressive stress $\sigma$ a sort of reaction to this constraint, that is negative values of $\sigma$ are non-constitutive (in the same way in which pressure is non-constitutive in incompressible materials). This model requires no material parameters since strength and stiffness in compression are assumed to be infinite whilst they are completely neglected in tension.

Model one (ENT). As a first step into the closer modelling of masonry behaviour one can consider to add a finite stiffness in compression: a linear ratio between stress and strain in compression is assumed. Another 
possibility would have been to add a limited strength in compression still assuming an infinite stiffness (rigid-plastic material), but in the vast majority of applications, the first ingredient to add appears to be elasticity since it allows to study the behaviour of the structure under working conditions, before collapse takes place. Most masonry constructions are indeed in a state of average stress that is well below the crushing strength, but the level of stress is such to trigger not only microscopic but also macroscopic brittle fracture.

Model one, described for a 1d bar by the plot of Figure 9c, is the so called Elastic No-Tension material, thoroughly studied since the late 70ties by the Italian school of structural mechanics (Romano and Romano (1979), Baratta and Toscano (1982), Como and Grimaldi (1985), Romano and Sacco (1985), Castellano (1988), Del Piero (1989), Angelillo (1993)).

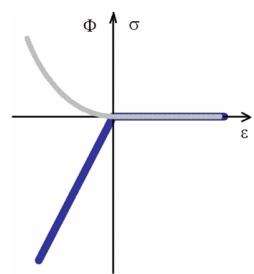

a.

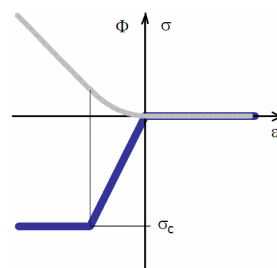

b.

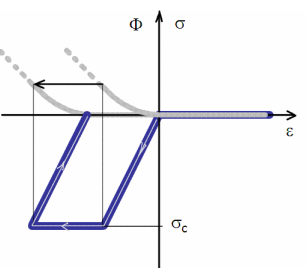

c.

Figure 10. In (a) elastic energy for model one, in (b) elastic energy for NT hyperelastic model with threshold. (c) elastic energy for model two.

Now the strain can be positive or negative, positive strain being the fracture part of deformation and negative strain the elastic part. The ENT material is globally elastic, in the sense that strain determines stress for any value of strain: now compressive stress is constitutive. The material is even hyperelastic since there exists a stored elastic energy density $\Phi$ such that $\sigma$ is the derivative of $\Phi$ with respect to $\epsilon$. The elastic energy corresponding to model one is depicted in Figure 10a. Notice that such energy, though convex, is not strictly convex (major source of mathematical and numerical troubles, see (Giaquinta and Giusti, 1985)).

This model requires only one material parameter: the elastic modulus $E$, since strength in compression is assumed to be infinite, whilst strength and stiffness are completely neglected in tension.

Model two (ML). A further step can be taken by adding to model one the assumption of a limited strength $\sigma_{c}$ in compression. In this way the failure modes due to crushing (such as those shown in Figure 3, but also, in a $2-3 \mathrm{~d}$ formulation, the failure modes and mechanisms represented 
in Figures 2, 5), can be modelled. Here we shall refer to model two, whose uniaxial behaviour is reported in Figure 9d, as the Masonry-Like material. Any attempt to enrich this model for real applications is usually frustrated by the lack of sufficient confidence on the material properties of the real materials and of their assemblages.

As depicted in Figure 9d, it is assumed that the material behaves as perfectly plastic in compression, therefore the constitutive response becomes incremental and the actual stress state is path dependent, being determined by the whole strain history. In Figure 10b the elastic energy of a path independent material having the same stress-strain plot of model two under monotone loading (that is a No-Tension hyperelastic material with threshold) is shown.

The incremental model is obviously not hyperelastic, though a sort of "path dependent" elastic energy can still be defined (as shown in Figure 10c for a special loading-unloading cycle). Now the anelastic part of deformation is further decomposed into a reversible fracture part and in a irreversible crushing part. We have to remark that this is a peculiar perfectly plastic material, since, due to the different behaviour in tension (elastic fracture) and compression (incremental plasticity), the plastic deformations cannot be cancelled by reversing the strain. This model requires the setting of two material parameters: the elastic modulus $E$ and the strength in compression $\sigma_{c}$, strength and stiffness being still completely neglected in tension.

Extension to 3d.For real applications the three simplified models need to be extended to $3 \mathrm{~d}$. The NT hypothesis translate in $3 \mathrm{~d}$ into an assumption that the stress $\mathbf{T}$ belongs to the cone $S y m^{-}$of negative semidefinite symmetric tensors.

The next step is to introduce convenient rules for the latent part of the deformation, that is for the strain sustaining the unilateral constraint on the stress. The usual simplifying assumption is that there is no sliding along the fracture lines, that is the total fracture strain satisfy a law of normality with respect to the cone $\mathrm{Sym}^{-}$of admissible stresses (equivalent to require that the stress do no work for the anelastic strain and that the anelastic strain is positive semidefinite).

The law of normality allows for the simple application of the theorems of limit analysis in $3 \mathrm{~d}$ : the static and the kinematic ones.

For what concerns model one the linear elastic assumption in compression is easily generalized if one restricts to isotropy; in such a case the definition of a further parameter: the Poisson ratio $\nu$ (a value that is difficult to be assessed through tests and is usually set between 0.1 and 0.2 ) is required.

The law of normality and the usual restrictions considered on the elastic 
constants, make the global response of model one in $3 \mathrm{~d}$ elastic, and even hyperelastic (see Del Piero (1989)), that is path independent. Also for model two the restriction to isotropy simplify things, but now, besides the material parameter $\sigma_{c}$, it is required to define a material function $f$, that is the limit surface in compression.

The flow rule for the increments of crushing strain must be also introduced; for simplicity one can choose to adopt an associated flow rule, also if the frictional nature of sliding under compression would require the adoption of a non-associated law.

Remark 1. Though the RNT model (model zero) appears as rather rudimentary (notice that it allows only to apply the theorems of limit analysis), it is the opinion of many master masons (among which Heyman (1995), Como (2010), and Huerta (2006)) that the RNT model is the only choice for old masonry constructions, the main motivation to this opinion being the impossibility for the elastic models to define correctly the initial state of the structure, due to the uncertainties about the boundary conditions and on the previous history.

Any elastic solution, that, in principle, would allow the definition of the stress state under the given loads, is indeed extraordinarily sensitive to very small variations of the boundary conditions, particularly to the change of the given boundary constraints such as those produced by the unknown settlements of the foundation. The idea for applying the elastic assumption (models one and $t w o$ ) is that the given settlements have been accommodated by means of a small displacement mechanism, that is a kind of rigid body relative displacement of some parts of the structure. The stress produced during the nucleation and growth of the fracture necessary to activate the mechanism are, in the end, almost completely released, and the final state that we see, can be used as an essentially stress free reference state. In the analysis of a real masonry artefact, it is up to the sensitivity of the analyzer, based on the signs that the structure exhibits, to judge if the construction seats or not in this comfortable state. $\diamond$

Remark 2. We have given reasons for adopting the simplified models, but it is obvious that doing so we forget about many mechanical properties of real masonry materials. Such properties can have a more or less fundamental role in the modelling and it is important to know them to fully appreciate the limits of validity of the simplified models. They are recorded in a "subjective" order of importance in the following list.

- There are signs of damage since the early stages of loading. Effect: non linear $\sigma-\epsilon$ plot and decline of stiffness.

- The behaviour in tension is brittle. Effect: energy is expended to open a crack. 
- The cracks are not purely normal, there is actually sliding and is ruled by friction.

- Ductility, if any, is rather limited.

- The elastic and anelastic response is anisotropic.

- The anelastic behaviour, initially of hardening type, turns soon into softening.

- The cyclic response is hysteretic and the stress-strain plots depends on the rates: viscoelastic behaviour is implied.

- The material shows signs of degradation (strength reduction) under long term loading.

- Sometimes the displacements are very large and demand for theories accounting for geometric nonlinearities.

Nowadays there would not be any difficulties, either analytical or numerical, to include all this effects (except brittleness, softening and friction) into a FEM simulation of the masonry structure. The point is that, as already remarked, the knowledge of these fine properties of masonry materials is often lacking, especially for old masonry.»

\section{Masonry behavior of regularly arranged masonry structures. Homogenization and refined models}

P. L nço and G. Milani

\subsection{Introduction}

Masonry is a heterogeneous assemblage of units and joints. Units are such as bricks, blocks, ashlars, adobes, irregular stones and others. Mortar can be clay, bitumen, chalk, lime/cement based mortar, glue or other. The huge number of possible combinations generated by the geometry, nature and arrangement of units as well as the characteristics of mortars raises doubts about the accuracy of the term "masonry". Still, much information can be gained from the study of regular masonry structures, in which a periodic repetition of the microstructure occurs due to a constant arrangement of the units (or constant bond).

The difficulties in performing advanced testing of this type of structures are quite large due to the innumerable variations of masonry, the large scatter of in situ material properties and the impossibility of reproducing it all in a specimen. Therefore, most of the advanced experimental research carried out in the last decades concentrated in brick block masonry and its relevance for design. Accurate modelling requires a comprehensive experimental description of the material, which seems mostly available at the present state 
of knowledge (Rots, 1997; Lourenço, 1998a). The behaviour of masonry is much dependant not only on the composition of units and joints, but also on how they are arranged and treated. Figure 11 shows two results of a set of tests on dry stone masonry joints under shear testing. The adopted stone is granite and the stone has been polished, sawn or artificially made rough with a random impact of a spike. It is clear that the same surface with different treatments has different capacities, with an initial tangent of the friction angle for the polished stone joint (equal to 0.18) much lower than the other surface treatments (about 0.6). The situation is even more dramatic for the initial dilatancy angle, which is about zero for the polished and sawn joints, but provides a dramatic volume loss for each load reversal due to compaction of the joints. This phenomenon contributes to interlocking loss between irregular masonry units and masonry out of plane collapse in case of an earthquake. Another interesting example on how the masonry meso-structure (i.e. the arrangement of units, usually referred to as micro-scale in masonry) influences the response is given in Vasconcelos and Lourenço (2009). Here, three different types of stone masonry walls with the same external geometry are tested under in plane cyclic shear, namely regular dry stone masonry, irregular mortared joints masonry and rubble masonry. Not only the strength and stiffness degradation of the walls is rather different but also the strength envelop found is much different, with a tangent of the friction angle varying between 0.4 (for dry stone masonry), 0.3 (for irregular masonry) and 0.2 (for rubble masonry).

The examples given demonstrate the relevance of the micro-structure of masonry for the structural response. Therefore, the global field of structural analysis of masonry structures encompasses several different approaches and a comprehensive review is given in Lourenço (2002), with a recent update for seismic analysis in Marques and Lourenço (2011) for masonry with box behaviour and in Lourenço et al. (2011) for masonry without box behaviour. Depending on the level of accuracy and the simplicity desired, usually the following representations are possible: (a) micro-modelling, where the geometry of units and joints is directly considered and the constitutive laws are obtained experimentally; (b) macro-modelling, where units and joints are smeared out in the continuum and the constitutive laws are obtained experimentally; (c) homogenization, where the micro-structure is handled mathematically in terms of geometry and material data to obtain a smeared continuum model; (d) structural component models, where constitutive laws of structural elements are directly provided in terms of internal forces such as shear force or bending moment (and related generalized displacements), instead of stresses and strains, see Figure 12. The present chapter focuses on masonry behaviour and numerical data, on the analysis of masonry struc- 


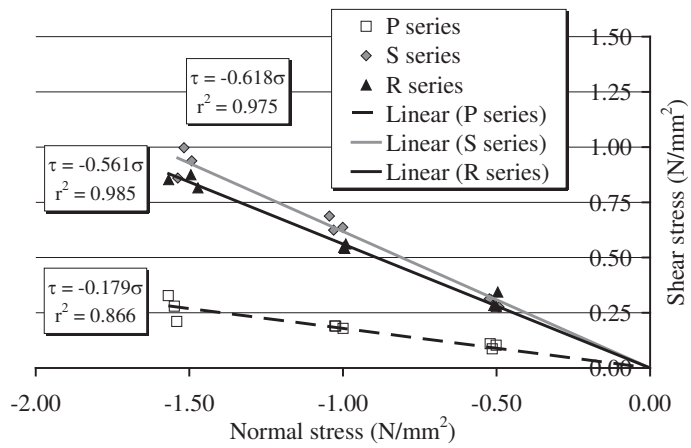

(a)

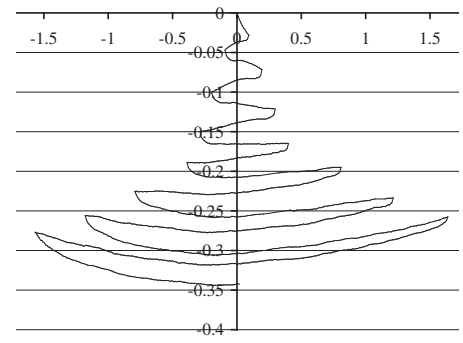

(b)

Figure 11. Testing of dry stone masonry joints under cyclic shearing, Lourenço and Ramos (2004): (a) Coulomb friction law for polished "P", sawn " $\mathrm{S}$ " and rough "R" surfaces; (b) dilatancy of the joints for "R" surface under reversed cycles, with the horizontal and vertical displacements of the joints in the respective axes, in $\mathrm{mm}$.

tures making use of homogenization techniques, which has been receiving a growing interest from the scientific community, see also Lourenço et al. (2007), and on the seismic analysis of masonry structures.

\subsection{Mechanical Behaviour of Masonry, Observations and Numer- ical Data}

A basic modern notion in the mechanical behaviour of masonry is softening, which is a gradual decrease of mechanical resistance under a continuous increase of deformation forced upon a material specimen or structure, see Figure 13. Softening is a salient feature of brick, mortar, stone or concrete, which fail due to a process of progressive internal crack growth. For tensile 


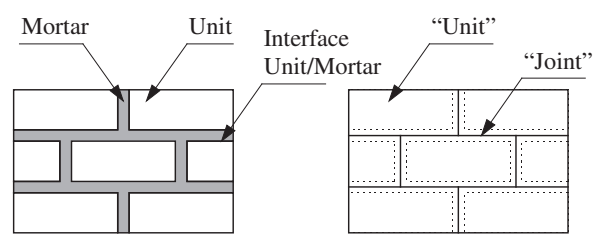

(a)

(b)

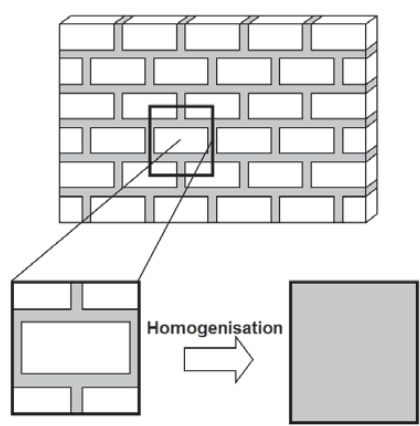

(d)

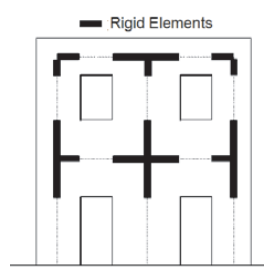

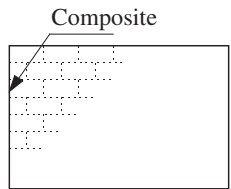

(c)

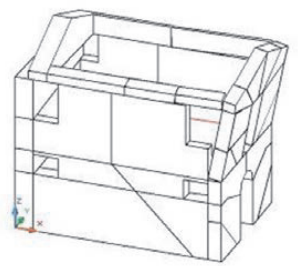

(e)

Figure 12. Modelling approaches for masonry: (a) representation of regular staggered or running bond masonry; (b) micro-modelling; (c) macromodelling; (d) homogenisation; (e) illustrative structural component models, with beam elements or macro-blocks. 
failure this phenomenon has been well identified. For shear failure, a softening process is also observed, associated with degradation of the cohesion in Coulomb friction models. For compressive failure, experimental data seems to indicate that both local and continuum fracturing processes govern the behaviour.
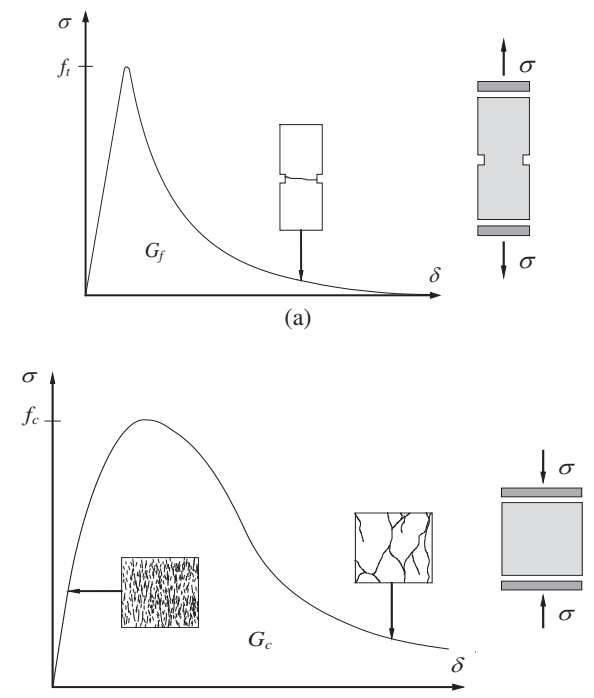

(b)

Figure 13. Softening and the definition of fracture energy: (a) tension; (b) compression. Here, $f_{t}$ equals the tensile strength, $f_{c}$ equals the compressive strength, $G_{f}$ equals the tensile fracture energy and $G_{c}$ equals the compressive fracture energy. It is noted that the shape of the non-linear response is also considered a parameter controlling the structural response. Nevertheless, for engineering applications, this seems less relevant than the other parameters.

Properties of unit and mortar The properties of masonry are strongly dependent upon the properties of its constituents. Compressive strength tests are easy to perform and give a good indication of the general quality of the materials used, but very few results exist in the uniaxial post-peak behaviour of compressed bricks and blocks, or mortar. The values proposed for concrete in the Model Code 90 (CEB-FIP, 1993) are a peak strain of $0.2 \%$ and a compressive fracture energy given by a parabolic best fit 
$G_{f, c}=15+0.43 f_{c}-0.0036 f_{c}^{2}$, with $f_{c}$ in $\mathrm{N} / \mathrm{mm}^{2}$ and $G_{f, c}$ in $\mathrm{N} / \mathrm{mm}$ This curve is only applicable for compressive strength value of $f_{c}$ between 12 and $80 \mathrm{~N} / \mathrm{mm}^{2}$. The average ductility index in compression $d_{u, c}$ (ratio between fracture energy and strength) is $0.68 \mathrm{~mm}$, even if this value changes significantly and it is recommended to use the above expression. For $f_{c}$ values lower than $12 \mathrm{~N} / \mathrm{mm}^{2}$, a $d_{u, c}$ value equal to $1.6 \mathrm{~mm}$ is suggested and for $f_{c}$ values higher than $80 \mathrm{~N} / \mathrm{mm}^{2}$, a $d_{u, c}$ value equal to $0.33 \mathrm{~mm}$ is suggested. These are the limits obtained from Model Code 90.

It is difficult to relate the tensile strength of the masonry unit to its compressive strength due to the different shapes, materials, manufacture processes and volume of perforations. For the longitudinal tensile strength of clay, calcium-silicate and concrete units, Schubert (1988) carried out an extensive testing program and obtained a ratio between the tensile and compressive strength that ranges from 0.03 to 0.10 .

Extensive information on the tensile strength of masonry units and their fracture energy is available, see e.g. van der Pluijm (1999), Lourenço et al. (2005) and Vasconcelos et al. (2008). The ductility index $d_{u}$, given by the ratio between the fracture energy $G_{f}$ and the tensile strength $f_{t}$, found for brick was between 0.018 and $0.040 \mathrm{~mm}$. The recommended ductility index $d_{u}$, in the absence of more information is the average, $0.029 \mathrm{~mm}$.

For stone granites, a non-linear relation given by $d_{u}=0.239 f_{t}^{-1.138}$ was proposed in Vasconcelos et al. (2008), with $d_{u}$ in $\mathrm{mm}$ and $f_{t}$ in $\mathrm{N} / \mathrm{mm}^{2}$. For an average granite tensile strength value of $3.5 \mathrm{~N} / \mathrm{mm}^{2}$, the $d_{u}$ value reads $0.057 \mathrm{~mm}$, which is the double of the suggested value for brick, possibly due to the larger grain structure of granite when compared to clay.

Finally, Model Code 90 (CEB-FIP, 1993) recommends for concrete (maximum aggregate size $8 \mathrm{~mm})$, the value of $G_{f}=0.025\left(f_{c} / 10\right)^{0.7}$, with $G_{f}$ in $\mathrm{N} / \mathrm{mm}$ and the compressive strength $f_{c}$ in $\mathrm{N} / \mathrm{mm}^{2}$. Assuming that the relation between tensile and compressive strength is about $5 \%$, the following expression is obtained $G_{f}=0.04 f_{t}^{0.7}$.

For the mortar, standard test specimens are cast in steel moulds and the water absorption effect of the unit is ignored, being usually not representative of the mortar inside the composite. Moreover, the interface between mortar and unit controls the behaviour of the joint in a large extent. For the tensile fracture energy of mortar, very few results are available, see PauloPereira (2012), and the average value of ductility found for different mortar compositions is $0.065 \mathrm{~mm}$.

Properties of the interface The research on masonry has been scarce when compared with other structural materials and experimental data which can be used as input for advanced non-linear models is limited. The bond 
between the unit and mortar is often the weakest link in masonry assemblages. The non-linear response of the joints, which is then controlled by the unit-mortar interface, is one of the most relevant features of masonry behaviour. Two different phenomena occur in the unit-mortar interface, one associated with tensile failure (mode I) and the other associated with shear failure (mode II).

Different test set-ups have been used for the characterisation of the tensile behaviour of the unit-mortar interface. These include (three-point, fourpoint, bond-wrench) flexural testing, diametral compression (splitting test) and direct tension testing. For the purpose of numerical simulation, direct tension tests is the one to be adopted as it allows for the complete representation of the stress-displacement diagram and yields the correct strength value, see Figure 14 .

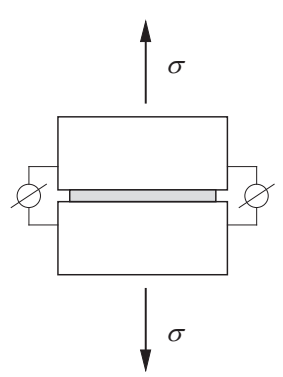

(a)

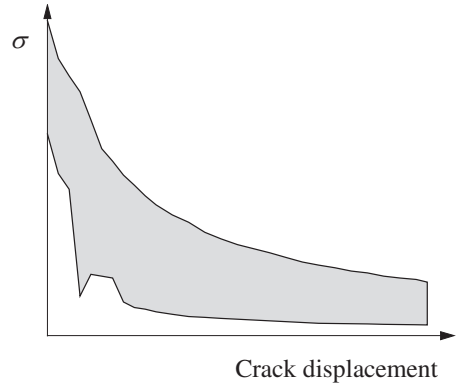

(b)

Figure 14. Tensile bond behaviour of masonry: (a) test specimen (direct tension); (b) typical experimental stress-crack displacement results for solid clay brick masonry (the shaded area represents the envelope of four tests), van der Pluijm (1999).

The parameters needed for the tensile mode (Mode I) are similar to the previous section, namely the bond tensile strength $\mathrm{ft}$ and the bond fracture energy $G_{f}$. The factors that affect the bond between unit and mortar are highly dependent on the units (material, strength, perforation, size, air dried or pre-wetted, etc.), on the mortar (composition, water contents, etc.) and on workmanship (proper filling of the joints, vertical loading, etc.). A recommendation for the value of the bond tensile strength based on the unit type or mortar type is impossible, but an indication is given in Eurocode 6 (CEN, 2005) for the characteristic value (95\% fractile), in the range of 0.1 to $0.4 \mathrm{~N} / \mathrm{mm}^{2}$. The value for Mode I fracture energy $G_{f, I}$ found for different 
combinations of unit and mortar was between $0.005 \mathrm{~mm}$ and $0.035 \mathrm{~mm}$, van der Pluijm (1999). This value is not dependent on the bond strength and the recommended fracture energy is the average value of $0.012 \mathrm{~N} / \mathrm{mm}$, in the absence of more information.

An important aspect in the determination of the shear response of masonry joints is the ability of the test set-up to generate a uniform state of stress in the joints. This objective is difficult because the equilibrium constraints introduce non-uniform normal and shear stresses in the joint. Different test set-ups have been used for the characterisation of the shear behaviour of the unit-mortar interface. These include direct shear or couplet test and triplet test, see Figure 15. The triplet test can hardly be used to obtain the post-peak characteristics because the joints do not fail simultaneously and a rotation is obtained, Lourenço et al. (2004), so a couplet test is recommended for this purpose. It is also noted that a key issue for obtaining the post-peak characteristics is to keep constant the stress normal to the bed joint during testing.

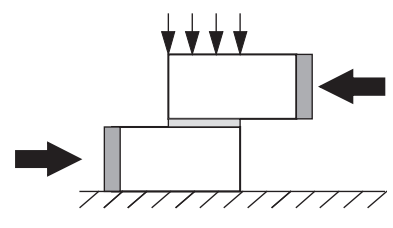

(a)

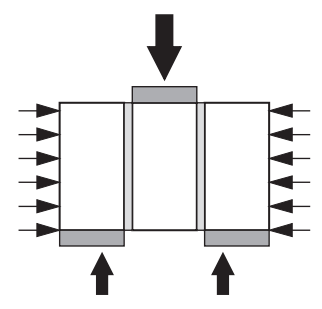

(b)

Figure 15. Possible test set-ups for shear strength: (a) couplet test; (b) triplet test.

Experimental results yield typically an exponential shear softening diagram with a residual dry friction level, see Figure 16a. The envelop of the shear strength for different normal stress values provides the cohesion and the friction angle for a Coulomb type friction model, see Figure 16b. A recommendation for the value of the bond shear strength (or cohesion) c based on the unit type or mortar type is impossible, but an indication is given in Eurocode 6 (CEN, 2005) for the characteristic value (95\% fractile), in the range of 0.1 to $0.4 \mathrm{~N} / \mathrm{mm}^{2}$. The ductility index $d_{u, s}$, given by the ratio between the fracture energy $G_{f, I I}$ and the cohesion $c$, found for different combinations of unit and mortar was between $0.062 \mathrm{~mm}$ and $0.147 \mathrm{~mm}$, van der Pluijm (1999). The recommended ductility index $d_{u, I I}$ is the average value of $0.093 \mathrm{~mm}$. It is noted that the Mode II fracture energy is clearly 
dependent of the normal stress level and the above values hold for a zero normal stress.

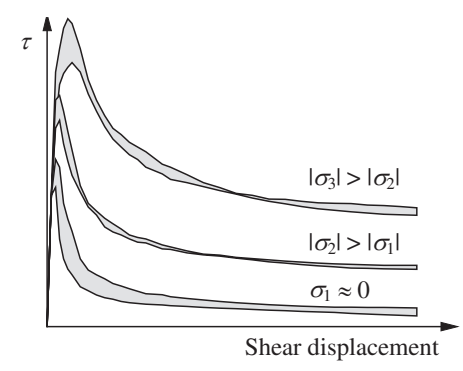

(a)

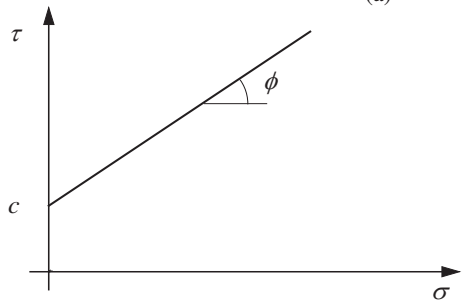

(b)

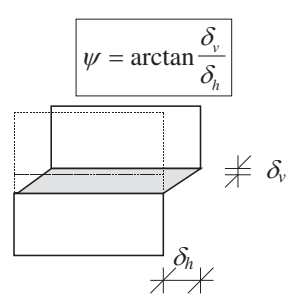

(c)

Figure 16. Shear bond behaviour: (a) typical stress-displacement diagram for different normal stress levels (the shaded area represents the envelope of three tests), van der Pluijm (1999); (b) cohesion $c$ and friction angle $\phi$, defining the envelop obtained with the shear strength for different compressive stresses; (c) dilatancy angle $\psi$ is the uplift of neighbouring units upon shearing

The friction angle of the joint $\phi$, associated with a Coulomb friction model, ranges from 0.7 to 1.2 for different unit-mortar combinations, van der Pluijm (1999), but different values are found in the literature. A value of 0.75 is recommended in the absence of more information. The dilatancy angle $\psi$ measures the uplift of one unit over the other upon shearing, see Figure 16c. Note that the dilatancy angle decreases to zero with increasing vertical stress and with increasing slip, so a zero value is recommended. The effect of the dilatancy angle is only relevant for applications in which masonry is confined, due to the interlocking effect of the units and the associated stress built-up. 
Properties of the masonry The compressive strength of masonry in the direction normal to the bed joints has been traditionally regarded as the most relevant structural masonry property. Since the pioneering work of Hilsdorf (1969) it has been accepted by the masonry community that the difference in elastic properties of the unit and mortar is the precursor of failure. Lourenço and Pina-Henriques (2006) demonstrated that continuum models are inadequate to justify the observed strength values in solid masonry and that there is a need to consider more refined models. Different formulas to predict the compressive strength of masonry based on the properties of the components are available and are compared by these authors. The formula available in Eurocode 6 (CEN, 2005) provides the characteristic value of masonry under uniaxial compression as $f_{k}=K f_{b}^{0.7} f_{m}^{0.3}$, where $K$ is factor about 0.5 for solid units, $f_{b}$ is the unit compressive strength and $f_{m}$ is the mortar compressive strength.

Uniaxial compression tests in the direction parallel to the bed joints have received substantially less attention from the masonry community. However, regular masonry is an anisotropic material and, particularly in the case of low longitudinal compressive strength of the units due to high or unfavourable perforation, the resistance to compressive loads parallel to the bed joints can have a decisive effect on the load bearing capacity. According to Hoffman and Schubert (1994), the ratio between the uniaxial compressive strength parallel and normal to the bed joints ranges from 0.2 to 0.8 .

For traditional masonry, information is available in PIET-70 (1971) for the compressive strength of stone masonry, varying between 8.0 and 0.5 $\mathrm{N} / \mathrm{mm}^{2}$ depending on the quality of the mortar, the type of stone and the masonry bond, and for different properties of different masonry types in OPCM 3431 (2005), varying between 6.0 and $0.6 \mathrm{~N} / \mathrm{mm}^{2}$.

The relation $E=\alpha f_{c}$ between the Young's modulus $E$ and the compressive strength $f_{c}$ is rather variable for masonry, with values of $\alpha$ ranging between 200 and 1000 according to Tomazevic (1999), even if the proposed value in Eurocode 6 (CEN, 2005) is 1000. For dry stone masonry, PIET-70 (1971) proposes a value of $\alpha=500$, which is in the mid-range of the interval of Tomazevic (1999) and is possibly more adequate for traditional masonry.

\subsection{Example of application}

Advanced non-linear analyses are not particularly sensitive to the input data, providing that the changes in the material properties are reasonable, see Lourenço (1998b) and Mendes (2012). Therefore, numerical results can be expected to reasonably replicate experimental tests and, in general, to provide a single response to a given combination of geometry, loading and 
materials. Next, an example of calculation of advanced material properties from basic data of the masonry constituents is given taking as an example a concrete block with two-cells and $10 \mathrm{~N} / \mathrm{mm}^{2}$ compressive strength $\left(f_{b}\right)$ and a mortar with $6 \mathrm{~N} / \mathrm{mm}^{2}$ compressive strength $\left(f_{m}\right)$. The geometry of the block is $0.14 \times 0.39 \times 0.19 \mathrm{~mm}^{3}(t \times l \times h)$ with a thickness $t_{s}$ for the shell walls equal to $25 \mathrm{~mm}$.

The properties required for a micro-modelling approach can be estimated as:

1. The bond tensile strength $\mathrm{ft}$ can be estimated at $0.2 \mathrm{~N} / \mathrm{mm}^{2}$ which is a minimum value for modern masonry, with the exception of very smooth units. The recommended bond tensile fracture energy is $0.012 \mathrm{~N} / \mathrm{mm}$.

2. The cohesion or shear strength can be estimated as $1.5 \mathrm{ft}$ or 0.3 $\mathrm{N} / \mathrm{mm}^{2}$ The recommended ductility index $d_{u, I I}$ is $0.093 \mathrm{~mm}$, providing a fracture energy for mode II of $0.028 \mathrm{~N} / \mathrm{mm}$. The recommended values for the tangent of the friction and dilatancy angle (in case of a non-associated model) are 0.75 and zero, respectively.

3. The masonry compressive strength (perpendicular to the bed joints) for this type of units can be safely estimated as $0.7 f_{b}$, providing a value of $7 \mathrm{~N} / \mathrm{mm}^{2}$. If the Eurocode 6 (2005) formula is used instead, a lower bound value would be $0.45 \times 10^{0.7} \times 6^{0.3} / 0.8=6 \mathrm{~N} / \mathrm{mm}^{2}$, where the 0.8 value is adopted to change from the characteristic to the mean value. The recommended ductility index $d_{u, c}$ is $1.6 \mathrm{~mm}$, providing a fracture energy for compression of $9.6 \mathrm{~N} / \mathrm{mm}$.

The properties required for a macro-modelling approach using an isotropic model are the same as above, adopting the tensile bond strength and compressive strength. If a macro-modelling approach with an anisotropic model is used, additional material properties are needed:

1. The masonry tensile strength perpendicular to the joints is controlled by the bed joint, being the same as above.

2. The masonry tensile strength parallel to the bed joints can be obtained as indicated next. Assuming a void ratio of $50 \%$, the compressive strength of concrete $f_{\text {conc }}$ is $20 \mathrm{~N} / \mathrm{mm}^{2}$. The tensile strength for a straight crack through head joints and blocks can be approximated to the strength of the block given by $10 \% \times f_{\text {conc }} \times 2 t_{s} \times h /(t \times 2 h)=$ $0.35 \mathrm{~N} / \mathrm{mm}^{2}$. The tensile strength for a stepped crack can be approximated by $c \times l / 2 / h=0.29 \mathrm{~N} / \mathrm{mm}^{2}$. The value to be used is the minimum of the two values $\left(0.29 \mathrm{~N} / \mathrm{mm}^{2}\right)$, being this response in shear fully plastic. Note that the tensile strength of the head joints was not used, as it is rather low and will not reach the peak value simultaneously with the other phenomena involved. 
3. The masonry compressive strength perpendicular to the joints is the same as above.

4. The masonry compressive strength parallel to the bed joints for this type of masonry can be estimated as $30 \%$ of the vertical strength, as a lower bound. This value can also can be calculated from Eurocode 6 as $0.35 \times\left(f_{\text {conc }} \times t_{s} \times 2 / t\right)^{0.7} \times 6^{0.3} / 0.8=3.0 \mathrm{~N} / \mathrm{mm}^{2}$. The recommended ductility index $d_{u, c}$ is $1.6 \mathrm{~mm}$, providing a fracture energy for compression of $4.8 \mathrm{~N} / \mathrm{mm}$.

\section{Bibliography}

M. Angelillo. Constitutive relations for no-tension materials. Meccanica, 28:195-202. 1993.

A. Baratta and R. Toscano. Stati tensionali in pannelli di materiale non resistente a trazione. In Atti del VII Congresso Nazionale AIMETA, 1982 (in Italian).

E. Benvenuto. An Introduction on the History of Structural Mechanics Part II: Vaulted Structures and Elastic Systems, Springer-Verlag. Springer Verlag, 1991.

G. Castellano. Un modello cinematico per i materiali non resistente a trazione. In Cinquantenario della Facoltà di Architettura di Napoli: Franco Jossa e la sua opera, pages 241-256, 1988 (in Italian).

CEB-FIP. Model Code 90. Thomas Telford Ltd., UK, 1993.

CEN. Eurocode 6: Design of masonry structures, Part 1-1: General rules for reinforced and unreinforced masonry structures. European Committee for Standardization, Belgium, 2005.

M. Como. Statica delle costruzioni storiche in muratura, Aracne. Aracne, 2010 (in Italian).

M. Como and A. Grimaldi. A unilateral model for the limit analysis of masonry walls. In Unilateral problems in structural analysis, edited by G. Del Piero and F. Maceri, CISM Courses and Lectures 288, Springer., pages $25-45,1985$.

G. Del Piero. Constitutive equation and compatibility of the external loads for linear elastic masonry-like materials. Meccanica, 24:150-162, 1989.

S. Di Pasquale. Statica dei solidi murari: teorie ed esperienze. Reports Dipartimento di Costruzioni, Univ. Firenze, 27, 1984 (in Italian).

M. Giaquinta and E. Giusti. Researches on the equilibrium of masonry structures. Arch. Rational Mech. Analysis, 88:359-392, 1985. ISSN 09502289.

J. Heyman. The stone skeleton. Int.J.Solids,Struct., 2:249-279, 1966.

J. Heyman. The stone skeleton: structural engineering of masonry architecture, Cambridge University Press. Cambridge University Press, 1995. 
H.K. Hilsdorf. Investigation into the failure mechanism of brick masonry loaded in axial compression. In F.H. Johnson, editor, Designing, engineering and constructing with masonry products, pages 34-41. Gulf Publishing Company, Houston, Texas, 1969.

G. Hoffman and P. Schubert. Compressive strength of masonry parallel to the bed joints. In N.G. Shrive and A. Huizer, editors, Proc. 10th Int. Brick and Block Masonry Conf., pages 1453-1462, Calgary, Alberta, 1994.

S. Huerta. Galileo was wrong: the geometrical design of arches. Nexus Network Journal, 8 (2):25-52, 2006.

P.B. Lourenço. Experimental and numerical issues in the modelling of the mechanical behaviour of masonry. In P. Roca and et al., editors, Proc. Structural analysis of historical constructions II, CIMNE, pages 57-91, Barcelona, 1998a.

P.B. Lourenço. Sensitivity analysis of masonry structures. In Proc. 8th Canadian Masonry Symp., pages 563-574, Jasper, Canada, 1998b.

P.B. Lourenço. Computations on historic masonry structures. Progress in Structural Engineering and Materials, 4(3):301-319, 2002.

P.B. Lourenço and J.L. Pina-Henriques. Validation of analytical and continuum numerical methods for estimating the compressive strength of masonry. Computers \& structures, 84(29):1977-1989, 2006.

P.B. Lourenço and L.F. Ramos. Characterization of cyclic behavior of dry masonry joints. Journal of Structural Engineering, 130(5):779-786, 2004.

P.B. Lourenço, J.O. Barros, and J.T. Oliveira. Shear testing of stack bonded masonry. Construction and Building Materials, 18(2):125-132, 2004.

P.B. Lourenço, J.C. Almeida, and J.A. Barros. Experimental investigation of bricks under uniaxial tensile testing. Masonry International, 18(1): $11-20,2005$.

P.B. Lourenço, G. Milani, A. Tralli, and A. Zucchini. Analysis of masonry structures: review of and recent trends in homogenization techniques this article is one of a selection of papers published in this special issue on masonry. Canadian Journal of Civil Engineering, 34(11):1443-1457, 2007.

P.B. Lourenço, N. Mendes, L.F. Ramos, and D.V. Oliveira. Analysis of masonry structures without box behavior. International Journal of Architectural Heritage, 5(4-5):369-382, 2011.

R. Marques and P.B. Lourenço. Possibilities and comparison of structural component models for the seismic assessment of modern unreinforced masonry buildings. Computers \& Structures, 89(21):2079-2091, 2011.

N. Mendes. Seismic assessment of ancient masonry buildings: Shaking table tests and numerical analysis. $\mathrm{PhD}$ thesis, University of Minho, Portugal, 2012 . 
F. Nardone. Analisi teorico-sperimentale di elementi murari rinforzati con FRP: Meccanismi resistenti e formule di progetto Degree thesis, University of Naples Federico II, Naples, 2006 (in Italian).

OPCM 3431 . Technical regulations for the design, assessment and seismic adaptation of buildings. Gazzetta Ufficiale Serie Generale n.107 del 10/05/2005, Italy, 2005.

M. Paulo-Pereira. Assessment of the seismic performance of building enclosures (in Portuguese). PhD thesis, University of Minho, Portugal, 2012.

PIET-70. P.I.E.T. 70 Masonry work. Prescriptions from Instituto Eduardo Torroja. Consejo Superior de Investigaciones CientÃyficas, Madrid (in Spanish), 1971.

G. Romano and M. Romano Sulla soluzione di problemi strutturali in presenza di legami costitutivi unilaterali. Rend. Accad. Naz. Lincei, 67: 104-113, 1979 (in Italian).

G. Romano and E. Sacco. Sul calcolo di strutture non resistenti a trazione. In Atti del VII Congresso Nazionale AIMETA ., pages 221-233, 1985 (in Italian).

J.G. Rots, editor. Structural masonry: An experimental/numerical basis for practical design rules. Balkema, Rotterdam, the Netherlands, 1997.

P. Schubert. The influence of mortar on the strength of masonry. In J.W. de Courcy, editor, Proc. 8th Int. Brick and Block Masonry Conf., pages 162-174, London, 1988. Elsevier Applied Science.

M. Tomazevic. Earthquake-resistant design of masonry buildings. Imperial College Press, London, 1999.

R. van der Pluijm. Out-of-plane bending of masonry: Behavior and Strenght. $\mathrm{PhD}$ thesis, Eindhoven University of Technology, The Netherlands, 1999.

G. Vasconcelos and P.B. Lourenço. In-plane experimental behavior of stone masonry walls under cyclic loading. Journal of structural engineering, 135(10):1269-1277, 2009.

G. Vasconcelos, P.B. Lourenço, C.A.S. Alves, and J. Pamplona. Experimental characterization of the tensile behaviour of granites. International journal of rock mechanics and mining sciences, 45(2):268-277, 2008. 